\title{
The Effect of Bridging Exercise to Improve Balance In Post Stroke Patients at Kartini Hospital Jepara
}

\author{
Mutiara Intani \\ Student of Physiotherapist Profession, Department of Physiotherapy, Universitas Muhammadiyah Surakarta, \\ Central Java, Indonesia
}

\begin{tabular}{l}
\hline \hline Article Info \\
\hline Article history: \\
Received: Sep 30, 2021 \\
Revised: Jan 31, 2022 \\
Accepted: Feb 27, 2022 \\
\hline
\end{tabular}

\section{Keywords:}

Balance;

Post Stroke;

Bridging Exercise.

\begin{abstract}
Stroke is a multi-factorial disease with various types of causes accompanied by major clinical manifestations and the main cause of disability and death in developing countries. Impaired standing balance in stroke patients is a very influential disorder and greatly disrupts the activities of post-stroke patients. With these problems, post-stroke patients have difficulty in carrying out independent activities so that they need a good balance. The body's ability to maintain balance or maintain a body of center is regulated by the higher central nervous system through the reception of nonimpulse regulation. One of the interventions given is bridging exercise. This exercise was measured using the Berg Balance Scale (BBS) outcome measurement. The purpose of this study was to determine the effect of bridging exercise to improve the balance of post-stroke patients at the Kartini Jepara Hospital. The research method uses an experimental study with a single case report approach. The study was conducted at a hospital in Jepara City on a post-stroke SNH patient named Mr. S, 65 years old, Muslim and a carpenter. Based on the results of the pre-test and post-test scores, it can be concluded that Bridging Exercise has an effect on the balance of post-stroke patients.
\end{abstract}

This is an open access article under the CC BY-NC license.

\section{Corresponding Author:}

Mutiara Intani,

Department of Physiotherapy,

Universitas Muhammadiyah Surakarta,

Jl. A Yani Pabelan, Kartasura, Tromol Pos 1, Surakarta 57102, Central Java, Indonesia

Email: Mutiaraintani51@gmail.com

\section{INTRODUCTION}

Stroke is a multi-factorial disease with various causes accompanied by major clinical manifestations and the main cause of disability and death in developing countries, one of which is Indonesia (Kooi et al., 2016) (Fatmawati \& Pradana, 2021). Meanwhile, according to the World Health Organization (WHO) stroke is the interruption of blood flow to the brain, generally due to rupture of blood vessels to the brain or due to blockage of blood vessels to the brain so that the supply of nutrients and oxygen to the brain is reduced (Kabi et al., 2015).

The prevalence of stroke in the United States is the number 5 cause of death with a prevalence of $2.6 \%$ aged 20 years, and $17.8 \%$ of those aged 45 years, while those who have experienced symptoms of stroke and cerebral infarction are about $6 \%$ to $28 \%$ of the growing population. with increasing age. 
The prevalence of stroke in Indonesia according to the 2013 Riskesdas, the highest incidence of stroke patients aged 75 years was $67 \%$, where $25 \%$ of men and $20 \%$ of women were found (Guzik \& Bushnell, 2017).

Cerebral damage can be classified into Ischemic Stroke (IS), which comprises $87 \%$ of cases and is caused by thrombotic occlusion of arteries and veins; or Intracerebral Hemorrhagic Strokes (ICHS), which comprise $13 \%$ of cases and are caused by rupture of a blood vessel by hypertension or aneurysm, trauma, and penetrating brain injury. Although ICHS is less common, ICHS is five times more fatal than IS (De Athayde Costa E Silva et al., 2020). Ischemic stroke is the death of brain tissue due to disruption of blood flow to the brain, caused by blockage of the cerebral or cervical arteries (Brenner, 2018).

Impaired standing balance in stroke patients is a very influential disorder and greatly disrupts the activities of post-stroke patients (de Haart et al., 2004) (Geurts et al., 2005). With these problems, post-stroke patients have difficulty in carrying out independent activities so that they need a good balance (Srivastava et al., 2010) (Srivastava et al., 2009) (Silhavy et al., 2018) (Robison et al., 2009). For this reason, post-stroke patients must be trained in muscle strength from the gluteus (buttocks) muscles, leg muscles, and lower back (Bale \& Inger Strand, 2008) (Lim et al., 2016). The body's ability to maintain balance or maintain a body of center is regulated by the higher central nervous system through the reception of non-impulse regulation. Information received from the sensory system is then synthesized in the Central Nervous System which is based on the schematic of the body and then each body responds which is formed through activation in maintaining muscle synergies according to head, eye, and limb movements to ensure balance maintenance (Lendraitiene et al., 2017). Some forms of exercise in stroke patients can be done by physiotherapy, one of which is bridging exercise, which is generally used for lumbo pelvic stabilization therapy because it can help coordinate general and local muscle development (Song \& Heo, 2015).

\section{RESEARCH METHOD}

This research uses the type of research in the form of an experimental study with a single case report approach. The study was conducted at a hospital in Jepara City on a post-stroke SNH patient named Mr. S, 65 years old, Muslim and a carpenter.

The outcome measurement used for the decrease in balance was assessed using the Berg Balance Scale (BBS) (Muir et al., 2008) (Lima et al., 2018). This scale has 14 items, each item is scored on a scale of o to 4 with a total score of 56 . This test takes about 20 minutes and only requires a stopwatch, a ruler, 2 types of chairs and a stepping/small stool. Subjects were declared to have postural balance disorders if the balance test results were $<46$. The interpretation of the BBS score of $41-56$ is considered a low risk of falling, while 21-40 is a moderate risk of falling, $\mathrm{O}-2 \mathrm{O}$ is a high risk of falling. BBS is a valid, reliable, and commonly used outcome measure in stroke rehabilitation.

A patient with the initials Mr. S is 65 years old with a medical diagnosis of left hemiparesis caused by an ischemic stroke. About 1 year ago, the patient suddenly felt weak in all of his left limbs when he woke up when he wanted to pray at dawn. Then the patient's family immediately took him to Kartini Hospital and immediately received treatment in the ER and a CT-Scan was immediately performed and the patient was treated for approximately 1 week (Jaaffar et al., 2011). The patient then continued outpatient physiotherapy (Hills \& Kitchen, 2007). 


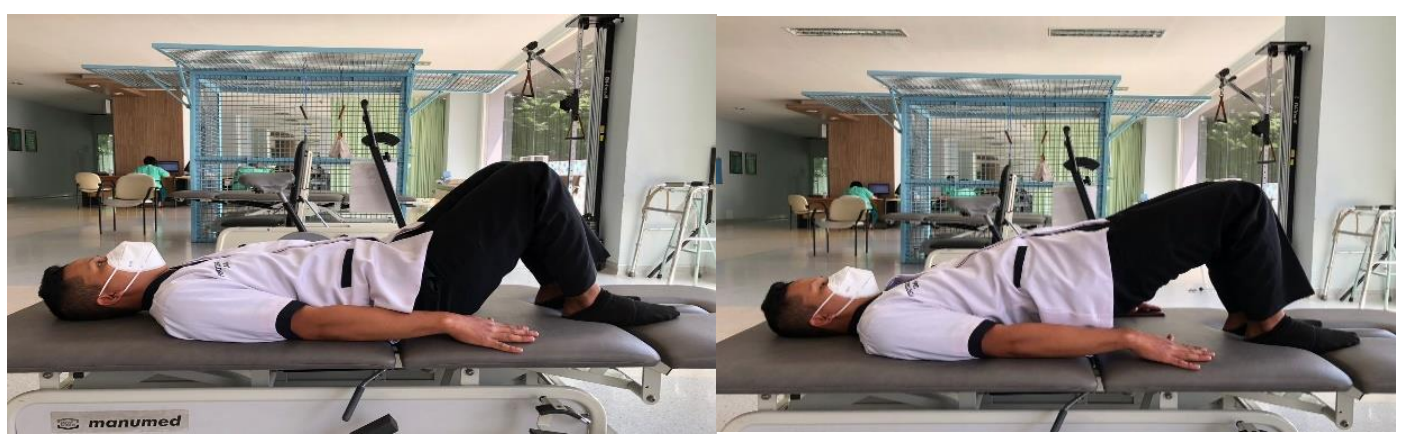

Figure 1. Bridging Exercise Technique

The techniques are For the bridge exercise, the subject bends the knee and lies down, lowering the arm at a shoulder angle of $30^{\circ}$, hip flexion $30^{\circ}$ knee flexion $90^{\circ}$ using the joint angle indicator and the distance between the legs according to shoulder width (Barber-Westin \& Noyes, 2016). Practice time is 30 minutes. The hip joint is maintained at $o^{\circ}$ for 8 seconds, the pelvis is lowered for 10 seconds to rest. 10 sessions per set of bridge training and a total of 3 sets that we did. Rest between sets is 60 seconds (Ynag \& Uhm, 2020).

\section{RESULTS AND DISCUSSIONS}

\subsection{Result}

Before conducting the training session that will be given, respondents took a pre-test to measure the patient's level of balance in stroke patients in the form of the Berg Balance Scale (BBS). After conducting the pre-test, respondents will be given training in the form of bridging exercise for 3 weeks with a frequency of exercise 2 times a week, this exercise is 6 times repetition, for 10 treatments. Furthermore, respondents will be measured post-test using the BBS scale according to the table below.

Table 1. Results of pre-test scores

\begin{tabular}{lll}
\hline No. & Tested Items & T1 \\
\hline 1. & Sitting to standing & 2 \\
\hline 2. & Standing unsupported & $\mathbf{1}$ \\
\hline 3. & Sitting unsupported & 4 \\
\hline 4. & Standing to sitting & 3 \\
\hline 5. & Transfers & 3 \\
\hline 6. & Standing with eyes closed & 3 \\
\hline 7. & Stand with feet together & 2 \\
\hline 8. & Reaching forward with outstretched arms & 2 \\
\hline 9. & Retrieving objects from floor & 3 \\
\hline 10. & Turning to look behind & 2 \\
\hline 11. & Turning 36o degrees & 2 \\
\hline 12. & Placing alternate foot on stool & 3 \\
\hline 13. & Standing with one foot in front & 3 \\
\hline 14. & Standing on one leg & 36 \\
\hline SCORE & & \\
\hline
\end{tabular}

Based on the table above, it was found that the post-test score was 36 , which means that the interpretation of the BBS score was that the patient had a low fall risk deficit.

Table 2. Results of pre-test and post-test scores

\begin{tabular}{clcc}
\hline No. & Tested Items & Pre-test & Post-test \\
\hline 1. & Sitting to standing & 2 & 2 \\
2. & Standing unsupported & 1 & 2 \\
3. & Sitting unsupported & 4 & 4 \\
4. & Standing to sitting & 3 & 3 \\
5. & Transfers & 3 & 3 \\
6. & Standing with eyes closed & 3 & 4 \\
\hline
\end{tabular}




\begin{tabular}{llcc}
\hline No. & Tested Items & Pre-test & Post-test \\
\hline 7. & Stand with feet together & 2 & 2 \\
8. & Reaching forward with outstretched arms & 2 & 3 \\
9. & Retrieving objects from floor & 3 & 4 \\
10. & Turning to look behind & 2 & 2 \\
11. & Turning 36o degrees & 2 & 2 \\
12. & Placing alternate foot on stool & 3 & 3 \\
13. & Standing with one foot in front & 2 & 3 \\
14. & Standing on one leg SCORE & 3 & 3 \\
& & 36 & 40 \\
\hline
\end{tabular}

Based on the table above, it can be seen that the pre-test score was 36 and the post-test score was 40. The interpretation of the BBS score of 56 was defined as a low fall risk deficit. On the results of the BBS score from the pre-test and post-test obtained, the degree of stroke has increased from 36 to 40, namely in the category of moderate fall risk deficit. It can be concluded that Bridging Exercise has an effect on the balance of post-stroke patients.

\subsection{Discussions}

This research is an experimental study with a single case report approach. Where it aims to determine the effect of Bridging Exercise on the level of balance in post-stroke patients. Respondents in this study were post-stroke patients who underwent outpatient treatment at the Kartini Hospital in Jepara. From the observation, there are post-stroke patients with balance problems sitting and standing as research subjects.

One of the problems in post-stroke patients is balance disorders, causing a greater risk of falling. Significantly, the decrease in post-stroke balance values was due to the influence of age, gender, and the length of time after having a stroke (Vincent-Onabajo et al., 2018). Balance control involves maintaining posture, facilitating movement, and restoring balance function. Balance can be maintained through the integration and coordination of the body's systems, including the visual, auditory, vestibular, and motor systems. There are several mechanisms related to balance control, namely sensory processes, biomechanical constraints, movement strategies, cognitive processes, and perceptions (Lendraitienè et al., 2017).

The results of the study on standing balance of post-stroke patients before being given bridging exercise intervention showed that the value of 35 while the balance score of stroke patients after intervention was 40, there was an increase in the balance score after the intervention was carried out, but this score was still $<46$ so it was still categorized as having postural balance disorders. Poststroke patients will definitely experience a decrease in muscle strength, this is the cause of post-stroke patients unable to use their muscles optimally. When muscles are not used, there will be a decrease in muscle strength and will cause balance disorders. Because disorders in the muscles will aggravate poststroke patients in carrying out daily activities of post-stroke patients. So post-stroke patients need to do bridging exercises. The bridging exercise intervention can increase the strength of the abdominal muscles, gluteus muscles, lower back, and hips which can improve the patient's standing balance after a blow.

This proves that bridging exercise can improve the sitting balance of non-hemorrhagic stroke patients. An increase in sitting balance due to bridging exercise in non-hemorrhagic stroke patients causes the process of contractile muscle protein synthesis to take place faster than the speed of delivery, resulting in progressively increasing number of actin and myosin filaments in the myofibrils. The myofibrils themselves will break down in each muscle fiber to form new myofibrils. An increase in the number of additional myofibrils causes the muscle to become hypertrophied. Hypertrophied muscle fibers have an increase in the components of the phosphagen metabolic system, including ATP and phosphocreatine. This results in an increase in the ability of aerobic and anaerobic metabolic systems which can increase energy and muscle strength (Guyton, 1997). This increase in muscle strength makes coordination better so that the patient can support the body and carry out movements. This is in line with the results of Karthikbabu (in Irma Suryani's research, 2012), who found that 
training the patient's body position in a conscious state can increase the symmetry of weight when sitting in subacute stroke.

Thus, it can be said that bridging exercise can improve the sitting balance of non-hemorrhagic stroke patients. Based on table 1, it is known the value of the respondent's balance ability before the intervention. However, after being given strengthening exercises 2 times a week for 4 weeks, it showed a difference before and after being given bridging exercise. An increase in sitting balance due to strengthening exercises has a positive effect on motor system function, body control and strengthening the muscles themselves. Research by Song \& Heo, (2015) on the effect of bridging exercise for poststroke patients has been carried out and it is concluded that bridging exercise improves the balance of stroke patients who experience hemiplegia.

\section{CONCLUSION}

It can be concluded that in this case, after the intervention in the form of bridging exercise for 8 meetings, the results showed that the balance value of the respondents had increased when compared between before and after the bridging exercise. This shows that there is an increase in bridging exercise on balance in post-stroke patients.

\section{REFERENCES}

Bale, M., \& Inger Strand, L. (20o8). Does functional strength training of the leg in subacute stroke improve physical performance? A pilot randomized controlled trial. Clinical Rehabilitation, 22(10-11), 911-921.

Barber-Westin, S. D., \& Noyes, F. R. (2016). Decreasing the risk of anterior cruciate ligament injuries in female athletes. Noyes' Knee Disorders: Surgery, Rehabilitation, Clinical Outcomes E-Book, 373.

Brenner, I. (2018). Effects of Passive Exercise Training in Hemiplegic Stroke Patients: A Mini-Review OPEN ACCESS. Sports Medicine and Rehabilitation Journal, 3(3), 1-6.

De Athayde Costa E Silva, A., Viana Da Cruz Júnior, A. T., Cardoso Do Nascimento, N. I., Andrade Candeira, S. R., Do Socorro Soares Cardoso Almeida, A., Santana De Castro, K. J., Costa De Lima, R., Generoso Campos Pinho Barroso, T., Da Silva Souza, G., \& Callegari, B. (2020). Positive Balance Recovery in Ischemic PostStroke Patients with Delayed Access to Physical Therapy. BioMed Research International, 1-8. https://doi.org/10.1155/2020/9153174

de Haart, M., Geurts, A. C., Huidekoper, S. C., Fasotti, L., \& van Limbeek, J. (2004). Recovery of standing balance in postacute stroke patients: a rehabilitation cohort study. Archives of Physical Medicine and Rehabilitation, 85(6), 886-895.

Fatmawati, A., \& Pradana, F. (2021). The Level of Knowledge, Motivation, and Self Efficacy of Post-Stroke Patients in Lumajang. Jurnal Ners Dan Kebidanan (Journal of Ners and Midwifery), 8(2), 201-205.

Geurts, A. C. H., De Haart, M., Van Nes, I. J. W., \& Duysens, J. (2005). A review of standing balance recovery from stroke. Gait $\mathcal{E}$ Posture, 22(3), 267-281.

Guzik, A., \& Bushnell, C. (2017). Stroke Epidemiology and Risk Factor Management. CONTINUUM Lifelong Learning in Neurology, 23(1), 15-39. https://doi.org/10.1212/CON.ooooooooooooo416

Hills, R., \& Kitchen, S. (2007). Satisfaction with outpatient physiotherapy: focus groups to explore the views of patients with acute and chronic musculoskeletal conditions. Physiotherapy Theory and Practice, 23(1), 1-20.

Jaaffar, A., Arshad, A., Karim, A., Mohamed, A., Zulkifli, A., Mamat, A., Alarhabi, A., Husin, A., Sharifuddin, A., \& Muhamad, A. (2011). Abstracts of Theses Approved for the MMed at the School of Medical Sciences, Universiti Sains Malaysia, Health Campus, Kubang Kerian, Kelantan, Malaysia. The Malaysian Journal of Medical Sciences: MJMS, 18(3), 87-169.

Kabi, G. Y. C. R., Tumewah, R., \& Kembuan, M. A. H. N. (2015). Gambaran Faktor Risiko Pada Penderita Stroke Iskemik Yang Dirawat Inap Neurologi Rsup Prof. Dr. R. D. Kandou Manado Periode Juli 2012 - Juni 2013. ECliniC, 3(1), 1-6. https://doi.org/10.35790/ecl.3.1.2015.7404

Kooi, C. W., Peng, H. C., Aziz, Z. A., \& Looi, I. (2016). A review of stroke research in Malaysia from 20oo-2014. Med J Malaysia, 71(Supplement 1).

Lendraitienė, E., Tamošauskaitė, A., Petruševičienė, D., \& Savickas, R. (2017). Balance evaluation techniques and physical therapy in post-stroke patients: A literature review. Neurologia i Neurochirurgia Polska, 51(1), 9210o. https://doi.org/10.1016/j.pjnns.2016.11.003

Lim, H. S., Kim, Y. L., \& Lee, S. M. (2016). The effects of Pilates exercise training on static and dynamic balance in chronic stroke patients: a randomized controlled trial. Journal of Physical Therapy Science, 28(6), 1819-1824.

Lima, C. A., Ricci, N. A., Nogueira, E. C., \& Perracini, M. R. (2018). The Berg Balance Scale as a clinical screening 
tool to predict fall risk in older adults: a systematic review. Physiotherapy, 104(4), 383-394.

Muir, S. W., Berg, K., Chesworth, B., \& Speechley, M. (2008). Use of the Berg Balance Scale for predicting multiple falls in community-dwelling elderly people: a prospective study. Physical Therapy, 88(4), 449-459.

Robison, J., Wiles, R., Ellis-Hill, C., McPherson, K., Hyndman, D., \& Ashburn, A. (2009). Resuming previously valued activities post-stroke: who or what helps? Disability and Rehabilitation, 31(19), 1555-1566.

Silhavy, R., Silhavy, P., \& Prokopova, Z. (2018). Evaluating subset selection methods for use case points estimation. Information and Software Technology, 97(June 2017), 1-9. https://doi.org/10.1016/j.infsof.2017.12.009

Song, G. Bin, \& Heo, J. Y. (2015). The effect of modified bridge exercise on balance ability of stroke patients. Journal of Physical Therapy Science, 27(12), 3807-3810. https://doi.org/10.1589/jpts.27.3807

Srivastava, A., Taly, A. B., Gupta, A., Kumar, S., \& Murali, T. (2009). Post-stroke balance training: role of force platform with visual feedback technique. Journal of the Neurological Sciences, 287(1-2), 89-93.

Srivastava, A., Taly, A. B., Gupta, A., \& Murali, T. (2010). Post-stroke depression: prevalence and relationship with disability in chronic stroke survivors. Annals of Indian Academy of Neurology, 13(2), 123.

Vincent-Onabajo, G., Musa, H. Y., \& Joseph, E. (2018). Prevalence of Balance Impairment Among Stroke Survivors Undergoing Neurorehabilitation in Nigeria. Journal of Stroke and Cerebrovascular Diseases, 27(12), 1-6. https://doi.org/10.1016/j.jstrokecerebrovasdis.2018.08.024

Ynag, D.-J., \& Uhm, Y.-H. (2020). Effects of Various Types of Bridge Exercise on the Walking Ability of Stroke Patients. The Journal of Korean Physical Therapy, 32(3), 137-145. https://doi.org/10.18857/jkpt.2020.32.3.137 